\title{
Technology Use to Deliver Faculty Development: A CERA Study
}

Suzanne Minor, MD | Suzanne Baker, MA | Joanna Drowos, DO, MPH, MBA | Jumana Antoun, MD, MS | Dennis Baker, PhD | Suzanne Leonard Harrison, MD | Alexander W. Chessman, MD

PRIMER. 2019;3:18.

Published: 8/15/2019 | DOI: 10.22454/PRiMER.2019.520410

\section{Abstract}

Introduction: Technology provides a platform to help address individualized training needs for community preceptors who are separated from the campus and pressured to achieve clinical productivity goals. This study explores technology use and support for delivering faculty development to community preceptors.

Methods: This cross-sectional study was part of the 2017 Council of Academic Family Medicine's (CAFM) Educational Research Alliance (CERA) annual survey of family medicine clerkship directors in the United States and Canada.

Results: The majority of respondents $(n=62,68.9 \%)$ agreed or strongly agreed that "using technology is critical to the successful delivery of faculty development to community preceptors." Only one-third $(n=31)$ agreed or strongly agreed that their institution offers them adequate support to create and deliver technology-mediated faculty development or offers adequate support to community preceptors for accessing and using technology.

Conclusions: Clerkship directors need institutional support to provide effective faculty development to preceptors via technology. The opportunity exists for institutions, national organizations, and professions to collaborate across disciplines and health professions on technology-based faculty development to support a level of quality and engagement for faculty development that is consistent with the levels we bring to student education.

\section{Introduction}

Faculty development is integral to medical education. Medical education programs increasingly rely on community preceptors and thus must prepare these preceptors through faculty development as required by medical education accrediting bodies. ${ }^{1,2}$ Faculty development by providing orientation and training are key barriers to recruiting community preceptors. ${ }^{3}$ Clerkship directors must engage community faculty in development activities in order to be successful. However, these directors often work distant from the university campus, face increasing productivity and time pressures, and have diverse training needs. ${ }^{4}$

While the literature provides examples of individual schools' implementation of technology-mediated preceptor development, no overall description of technology use exists in the literature. ${ }^{5-14}$ While medical educators use technology to educate students, technology is not leveraged similarly for faculty development. ${ }^{15}$ In this study, we explored family medicine clerkship director engagement with technology to deliver faculty development to community preceptors, including the level of institutional support available and desired. 


\section{Methods}

Data were gathered and analyzed as part of the 2017 Council of Academic Family Medicine's (CAFM) Educational Research Alliance (CERA) survey of family medicine clerkship directors. CAFM is a joint initiative of four major academic family medicine organizations: Society of Teachers of Family Medicine, North American Primary Care Research Group, Association of Departments of Family Medicine, and Association of Family Medicine Residency Directors. ${ }^{16-19}$ The cross-sectional survey is distributed annually to clerkship directors or their designee, at qualifying accredited medical schools by the Liaison Committee on Medical Education or Committee on Accreditation of Canadian Medical Schools within the United States and Canada. In 2017, there were 125 US and 16 Canadian unique individuals identified as family medicine educators directing family medicine or primary care clerkships. Approved projects were assigned a CERA research mentor to help refine questions. Final survey questions were modified following research mentor review.

The survey ${ }^{20}$ was distributed via email between June 28, 2017 and August 4, 2017. Two US emails were undeliverable, reducing the final sample size to 139. Invitations to participate included a personalized greeting and letter signed by the presidents of each of the four sponsoring organizations with a link to the online SurveyMonkey survey. Nonrespondents received weekly requests and were contacted through personal email to verify their status as clerkship directors, confirm email addresses, and encourage participation. The American Academy of Family Physicians Institutional Review Board approved the study.

We imported the deidentified data set provided by CERA into Statistical Package for the Social Sciences (SPSS) statistical software, version 23, (IBM SPSS Inc., Armonk, NY) for data analysis. We conducted descriptive and bivariate statistical analysis. Bivariate analysis was performed between the participants' statements about how technology is critical, the presence of institutional support to the clerkship director and institutional support to the community preceptor, and the various characteristics of clerkships and clerkship directors using $\chi^{2}$ analysis for categorical variables and one-way analysis of variance for continuous variables. We set significance at $P<.05$. All percentages are based on the number of valid responses; missing values were omitted.

\section{Results}

A total of 99 of 139 (71.2\%) clerkship directors responded to the survey. Table 1 presents the characteristics of responding clerkship directors and medical schools.

Table 2 describes clerkship director beliefs regarding the importance of technology in faculty development and the level of institutional support. The majority of respondents $(n=62,68.9 \%)$ agreed or strongly agreed that "using technology is critical to the successful delivery of faculty development to community preceptors," while $4.3 \%(n=4)$ disagreed or strongly disagreed. Only one-third $(n=31)$ agreed or strongly agreed that their institution offers adequate support to create and deliver technology-mediated faculty development or offers adequate support to community preceptors for accessing and using technology, highlighting the disparity between clerkship director needs and available institutional support. There was a positive correlation between clerkship directors' agreement that technology is critical for delivery of faculty development and agreement that their institution offers adequate support to create and deliver technology-mediated faculty development for community preceptors $(P=.01)$.

Table 3 outlines types of technologies currently utilized by clerkship directors to deliver faculty development. The majority used more than one technology to deliver faculty development to community preceptors. The most commonly used technology was asynchronous communication such as email or texting, and the least commonly used was social media such as Facebook or Twitter.

Table 4 outlines clerkship directors' beliefs about available technology support for delivery of faculty development for current faculty development programs, as well as anticipated support needs over the next 2 years. 


\section{Discussion}

This study provides a broad overview of the use of technology by family medicine clerkship directors to deliver faculty development to community preceptors, highlighting opportunities for innovation and improved practice. There was a negative relationship between years since graduation and agreement with the statement "using technology is critical to the successful delivery of faculty development to community preceptors." This finding implies that more recent graduates from residency may value technology more than those further removed from residency. Recent graduates may have utilized technology more during their own training, possibly contributing to higher regard for technology-facilitated learning. It is also possible that some clerkship directors lack awareness of potential opportunities for technology to supplement or foster face-to-face interactions with community preceptors.

Only one-third of clerkship directors agreed that their institution offers adequate support for the delivery of technology-mediated faculty development. The need for support of the family medicine clerkships represents an opportunity for technology-mediated faculty development for community faculty not just in this one clerkship, but across all clerkships and professions at an institution. Faculty development materials are already offered across institutions at the national level. Further study is needed to determine optimal leverage points for collaboration in creating preceptor development resources, both locally and nationally.

The majority of clerkship directors used asynchronous communication such as texting and email to deliver faculty development, in contrast to more interactive technologies favored for deeper and more durable learning. Future studies might assess why clerkship directors prefer to use asynchronous communication to deliver faculty development; motivations might include ease of use and familiarity with asynchronous communication or concern for community preceptor comfort or familiarity with technology-mediated instruction.

Study limitations include CERA limiting surveys to 10 questions per topic. This survey addresses only family medicine clerkship directors; community preceptors or clerkship directors from other specialties may view the use of technology differently.

\section{Conclusions}

Clerkship directors remain challenged with delivering faculty development to community preceptors. Technologymediated faculty development offers convenience, flexibility, and timely content; most clerkship directors agree that technology-mediated development is important. To innovate more extensively with technology-facilitated delivery, many clerkship directors will need additional assistance, including institutional support as well as training for competency with using innovative technologies to deliver faculty development.

\section{Tables and Figures}


Table 1: Characteristics of Responding Clerkship Directors and Medical Schools, 2017

\begin{tabular}{|c|c|}
\hline Demographics & n $(\%)$ \\
\hline Gender & Female (57/96) 59 \\
\hline Ethnicity & Non-Hispanic or Latino (92/95) 97 \\
\hline Race & White $(73 / 95) 77$ \\
\hline Years in Clerkship Director Role & n (\%) \\
\hline Less than 5 & $43(44)$ \\
\hline $5-10$ & $41(42)$ \\
\hline More than 10 & $13(13)$ \\
\hline Total & $97(99)$ \\
\hline \multicolumn{2}{|l|}{ Mean 6.38 (SD 5.06) } \\
\hline $\begin{array}{l}\text { Percentage of Protected Time for } \\
\text { Clerkship Director Role }\end{array}$ & n (\%) \\
\hline Less than $20 \%$ & $13(13)$ \\
\hline $20 \%-29 \%$ & $31(31)$ \\
\hline $30 \%-39 \%$ & $29(29)$ \\
\hline $40 \%-49 \%$ & $14(14)$ \\
\hline $50 \%-59 \%$ & $9(9)$ \\
\hline $60 \%$ or more & $2(2)$ \\
\hline Total & $98(100)$ \\
\hline \multicolumn{2}{|l|}{ Mean $28.91 \%$ (SD 12.66) } \\
\hline Years Since Residency & $\mathrm{n}(\%)$ \\
\hline $0-10$ & $26(27)$ \\
\hline $11-20$ & $35(36)$ \\
\hline $21-30$ & $21(22)$ \\
\hline More than 30 & $15(15)$ \\
\hline Total & $97(100)$ \\
\hline \multicolumn{2}{|l|}{ Mean 17.8 (SD 10.1) } \\
\hline $\begin{array}{l}\text { Characteristics of Participating } \\
\text { Medical Schools, } 2017\end{array}$ & $\mathrm{n}(\%)$ \\
\hline Public institutions & $67 / 98(68)$ \\
\hline Number of Medical Students & n $(\%)$ \\
\hline Less than 100 & $18(18)$ \\
\hline $100-199$ & $62(63)$ \\
\hline $200-299$ & $17(17)$ \\
\hline 30 or more & $2(2)$ \\
\hline Total & $99(100)$ \\
\hline Number of Regional Campuses & n (\%) \\
\hline None & $36(38)$ \\
\hline $1-9$ & $59(61)$ \\
\hline 10 or more & $1(1)$ \\
\hline Total & $96(100)$ \\
\hline
\end{tabular}


Table 2: Clerkship Directors' Beliefs Regarding Importance of Technology in Delivering Faculty Development and Adequacy of Institution Support for Clerkship Director and Community Preceptors

\begin{tabular}{|c|c|c|c|c|c|c|}
\hline Statement & $\begin{array}{l}\text { Strongly } \\
\text { Agree } \\
\text { n (\%) }\end{array}$ & $\begin{array}{l}\text { Agree } \\
\mathbf{n}(\%)\end{array}$ & $\begin{array}{l}\text { Neutral } \\
\text { n }(\%)\end{array}$ & $\begin{array}{l}\text { Disagree } \\
\text { n (\%) }\end{array}$ & $\begin{array}{l}\text { Strongly } \\
\text { Disagree } \\
\mathrm{n}(\%)\end{array}$ & $\begin{array}{l}\text { Total } \\
\text { n }(\%)\end{array}$ \\
\hline $\begin{array}{l}\text { Using technology is critical to the successful } \\
\text { delivery of faculty development to community } \\
\text { preceptors. }\end{array}$ & $22(23.7)$ & $42(45.2)$ & $25(26.9)$ & $3(3.2)$ & $1(1.1)$ & $93(100)$ \\
\hline $\begin{array}{l}\text { My institution offers me adequate support to } \\
\text { create and deliver technology-mediated faculty } \\
\text { development for community preceptors. }\end{array}$ & $4(4.3)$ & $27(29)$ & $21(22.6)$ & $34(36.6)$ & $7(7.5 \%)$ & $93(100)$ \\
\hline $\begin{array}{c}\text { My institution offers adequate support to } \\
\text { community preceptors for access and use } \\
\text { of technology-mediated faculty development } \\
\text { materials. }\end{array}$ & $3(3.3)$ & $26(28.3)$ & $24(26.1)$ & $27(29.3)$ & $12(13)$ & $92(100)$ \\
\hline
\end{tabular}

Table 3: Technology Currently Being Used to Deliver Faculty Development to Community Preceptors

\begin{tabular}{|c|c|}
\hline Technology & $n(\%)^{*}$ \\
\hline Synchronous communication such as video chatting or conferencing $(n=92)$ & $15(16.3)$ \\
\hline $\begin{array}{c}\text { Self-paced videos or media such as YouTube videos, webinars, voice-over PowerPoint presentations or podcasts } \\
(\mathrm{n}=92)\end{array}$ & $26(28.3)$ \\
\hline Self-paced readings such as e-newsletter $(\mathrm{n}=91)$ & $43(47.3)$ \\
\hline Online interactive modules that respond to participant choices $(n=88)$ & $10(11.4)$ \\
\hline Social media such as Facebook and Twitter $(n=89)$ & $4(4.5)$ \\
\hline Asynchronous communication such as email and texting messaging $(n=92)$ & $81(88)$ \\
\hline
\end{tabular}

${ }^{*}$ Respondents selected all that apply, thus total percentage adds up to more than 100 . 
Table 4: Clerkship Directors' Beliefs Regarding Available Technology Support for Current Faculty Development Program and Anticipated Support Needs Over the Next 2 Years

\begin{tabular}{|c|c|c|}
\hline Type of Support & $\begin{array}{c}\text { What Types of Support Do } \\
\text { You Rely Upon to Deliver } \\
\text { Your Current Faculty } \\
\text { Development Program? } \\
\text { n (\%)* }\end{array}$ & $\begin{array}{c}\text { To Improve Your Faculty } \\
\text { Development Program for } \\
\text { Community Preceptors, Over } \\
\text { the Next } 2 \text { Years, What Kind of } \\
\text { New Support Will You Need? } \\
n(\%)^{*}\end{array}$ \\
\hline $\begin{array}{l}\text { Timely in-person assistance with technology to deliver } \\
\text { faculty development }\end{array}$ & $29(35.4)$ & $36(41.1)$ \\
\hline $\begin{array}{c}\text { Assistance with the technical aspects of making faculty } \\
\text { development materials }\end{array}$ & $26(31.7)$ & $57(65.5)$ \\
\hline $\begin{array}{l}\text { Instructional design support to create or improve faculty } \\
\text { development materials }\end{array}$ & $28(34.1)$ & $57(65.5)$ \\
\hline $\begin{array}{c}\text { Assistance with integrating technological tools and } \\
\text { products into the clerkships faculty development } \\
\text { curriculum }\end{array}$ & $19(23.2)$ & $57(65.5)$ \\
\hline $\begin{array}{l}\text { Timely in-person assistance with technology for } \\
\text { preceptors to access faculty development }\end{array}$ & $18(22)$ & $45(51.7)$ \\
\hline $\begin{array}{l}\text { Institutional champions encouraging the use of } \\
\text { technology in faculty development }\end{array}$ & $25(30.5)$ & $40(46)$ \\
\hline I don't need any support. & $14(17.1)$ & $5(5.7)$ \\
\hline
\end{tabular}

*Respondents selected all that apply thus total percentage adds up to more than 100 . Note all percentages are valid, and missing values are omitted.

\section{Acknowledgments}

Presentations: Portions of this study were presented at the 2018 Society of Teachers of Family Medicine 2018 Conference on Medical Student Education in Austin, TX.

\section{Corresponding Author}

Suzanne Minor, MD

Office of Medical Education, Florida International University Herbert Wertheim College of Medicine, 11200 SW 8th St, AHC II, 458, Miami, FL 33199. 305-348-1455. Fax: 305-348-6107

seminor@fiu.edu

\section{Author Affiliations}

Suzanne Minor, MD - Florida International University Herbert Wertheim College of Medicine, Office of Medical Education, Miami, FL

Suzanne Baker, MA - Florida State University College of Medicine, Tallahassee, FL

Joanna Drowos, DO, MPH, MBA - Florida Atlantic University Charles E. Schmidt College of Medicine, Boca Raton, FL Jumana Antoun, MD, MS - Department of Family Medicine, American University of Beirut, Beirut, Lebanon Dennis Baker, PhD - Alabama College of Osteopathic Medicine, Dothan, AL

Suzanne Leonard Harrison, MD - Florida State University College of Medicine, Tallahassee, FL

Alexander W. Chessman, MD - Department of Family Medicine, Medical University of South Carolina, Charleston, SC

\section{References}

1. Liaison Committee on Medical Education. Functions and Structure of a Medical School: Standards for Accreditation of Medical Education Programs Leading to the MD Degree. Washington, DC: Liaison Committee 
on Medical Education; 2016.

2. Commission on Osteopathic College Accreditation. COM Accreditation Standards Crosswalk and Documentation Pad. Chicago, IL: American Osteopathic Association; 2016. Revised July 1, 2016.

3. Erikson C. Recruiting and maintaining U.S. clinical training sites: joint report of the 2013 Multi-discipline Clerkship/Clinical Training Site Survey. Washington, DC: American Association of Colleges of Osteopathic Medicine. https://members.aamc.org/eweb/upload/13-225\%20WC\%20Report\%202\%20update.pdf. Accessed February 20, 2017.

4. Langlois JP, Thach SB. Bringing faculty development to community-based preceptors. Acad Med. 2003;78(2):150-155. https://doi.org/10.1097/00001888-200302000-00009

5. Bramson R, Vanlandingham A, Heads A, Paulman P, Mygdal W. Reaching and teaching preceptors: limited success from a multifaceted faculty development program. Fam Med. 2007;39(6):386-388.

6. Kollisch DO, Gephart D, Brooks WB, Gagne R, Allen C, Donahue D. Impact of a preceptor education board and computer network to engage community faculty at Dartmouth Medical School. Acad Med. 1999;74(1) (suppl):S70-S74. https://doi.org/10.1097/00001888-199901000-00035

7. Baldwin CD, Niebuhr VN, Sullivan B. Meeting the computer technology needs of community faculty: building new models for faculty development. Ambul Pediatr. 2004;4(1)(suppl):113-116. https://doi.org/10.1367 /1539-4409(2004)0042.0.C0;2

8. Bulik RJ, Frye AW, Callaway MR, Romero CM, Walters DJ. Clinical performance assessment and interactive video teleconferencing: an iterative exploration. Teach Learn Med. 2002;14(2):124-132. https://doi.org /10.1207/S15328015TLM1402_10

9. Klein M, Niebuhr V, D'Alessandro D. Innovative online faculty development utilizing the power of social media. Acad Pediatr. 2013;13(6):564-569. https://doi.org/10.1016/j.acap.2013.07.005

10. Willett LR. Brief report: utilizing an audiotape for outpatient preceptor faculty development. J Gen Intern Med. 2006;21(5):503-505. https://doi.org/10.1111/j.1525-1497.2006.00437.x

11. Malik R, Bordman R, Regehr G, Freeman R. Continuous quality improvement and community-based faculty development through an innovative site visit program at one institution. Acad Med. 2007;82(5):465-468. https://doi.org/10.1097/ACM.0b013e31803ea942

12. Lie D, Boker J, Dow E, et al. Attributes of effective community preceptors for pre-clerkship medical students. Med Teach. 2009;31(3):251-259. https://doi.org/10.1080/01421590802139765

13. Scott SM, Schifferdecker KE, Anthony D, et al. Contemporary teaching strategies of exemplary community preceptors-is technology helping? Fam Med. 2014;46(10):776-782.

14. Society of Teachers of Family Medicine. Teaching Physician. (https://www.teachingphysician.org/). Accessed January 5, 2018.

15. Wong K, Swamy L, Jardine DA. \#TipsForNewDocs: Mentoring from miles away. J Grad Med Ed. 2017;9(5):674-675.

16. Association of American Medical Colleges. Effective Use of Educational Technology in Medical Education. 2007. https://members.aamc.org/eweb/upload/Effective\%20Use\%20of\%20Educational.pdf.

17. Mainous AG III, Shokar NK, Seehusen D. CAFM Educational Research Alliance (CERA) 2011 Residency director survey: background, methods and respondent characteristics. Fam Med. 2012;44(10):691-3.

18. Shokar N, Bergus G, Bazemore A, et al. Calling all scholars to the council of academic family medicine educational research alliance (CERA). Ann Fam Med. 2011;9(4):372-373. https://doi.org/10.1370/afm.1283

19. Seehusen DA, Mainous AG III, Chessman AW. Creating a centralized infrastructure to facilitate medical education research. Ann Fam Med. 2018;16(3):257-260. https://doi.org/10.1370/afm.2228

20. Minor, S. Use of Technology in Faculty Development for Community-based Preceptors: Clerkship Director CERA Survey 2017. STFM Resource Library. https://resourcelibrary.stfm.org/viewdocument/cd-cera-survey2017-use-of-technol?CommunityKey=2751b51d-483f-45e2-81de-4faced0a290a\&tab=librarydocuments. Accessed August 9, 2019. 